\title{
A NOTE ON THE MICRO-TEXTURE OF THE ARLTUNGA METEORITE.
}

\author{
By A. B. Edwards, Ph.D., D.I.C., \\ Research Officer, Mineragraphy Branch, Council for Scientific and Industrial Research.
}

(Figure 1.)

The Arltunga meteoritic iron is of interest because its micro-texture, as might be expected from its composition $(10.22 \% \mathrm{Ni})$, illustrates a stage in the development of the Widmanstätten structure, which is intermediate between the incipient stage, as shown in the Tawallah Valley iron (16.90\% Ni) (Hodge-Smith and Edwards, 1941), and the fully developed structure of the octahedrites proper $(6 \%-8 \% \mathrm{Ni})$.

Mawson (1934), who described the Arltunga iron, and classed it as an ataxite or micro-octahedrite, gained the impression at the magnification at which he worked (up to 500 diameters) that the fine octahedral structure of the iron arose from the alignment in octahedral fashion of "taenite rods . . . embedded in a directionless kamacite nickel-iron alloy low in nickel content" (1934, p. 2, and description of Plate i, Fig. 4). Such a structure is inconsistent with the explanation of the origin of the Widmanstätten structure put forward to explain the micro-texture of the Tawallah Valley iron (Hodge-Smith and Edwards, 1941, p. 6), which called for the development of ex-solution bodies of a-nickel-iron (kamacite) in the octahedral directions of the original $\gamma$-nickel-iron (taenite). In meteorites with a lower $\mathrm{Ni}$ content than the Tawallah Valley iron, the transformation to a-iron is more complete, and the ex-solution bodies develop into parallel plates, the residual high nickel $\gamma$-iron being trapped as thin lamellae between the plates of a-iron. The structure of the Arltunga iron as interpreted by Mawson would be the reverse of this.

A mineragraphic examination was made, therefore, of the small piece of the Arltunga iron lodged in the Australian Museum. A polished section was prepared on a Vanderbilt polishing machine, and examined at magnifications up to 1,000 diameters. The results indicated that Mawson was mistaken in his identification of the rods and blebs of the structure as $\gamma$-iron (taenite), and that the octahedral structure is due to the alignment in octahedral fashion of small plates of a-iron (kamacite) about 1/1,000 to $1 / 2,000$ inch thick, interleaved with still smaller plates of $\gamma$-iron (taenite), which have a maximum width of $1 / 20,000$ inch. These latter plates are only visible at high magnification, and with the high degree of polish obtainable with the polishing machine. Fig. 1 shows a field of view magnified by 800 diameters, in which the a-iron (kamacite) has a roughened surface, resulting from etching with $2 \% \mathrm{HNO}_{3}$ in alcohol, while the interleaved $\gamma$-iron (taenite) has a smooth, unetched surface.

The etching behaviour of these two components when treated with standard mineragraphic etching reagents conforms with the behaviour of undoubted a-iron (kamacite) and $\gamma$-iron (taenite) respectively (Edwards and Baker, 1942, pp. 10-11). The broader a-iron bands are immediately etched by $\mathrm{HNO}_{3}$, but without effervescence; $\mathrm{HCl}$ fumes tarnish them brownish, but the action is not consistent; $\mathrm{KOH}$ and $\mathrm{KCN}$ are negative; $\mathrm{FeCl}$ instantly turns the iron brown to black, bringing up the grain boundaries; $\mathrm{HgCl}_{2}$ darkens the surface immediately.

The thinner $\gamma$-iron bands remain unattacked by any of these reagents, with the doubtful exception of $\mathrm{HCl}$, which sometimes tarnished them.

This revised interpretation of the micro-structure is consistent with that shown by other meteoritic irons, and with the theory previously referred to; and it is suggested that this iron should be classed, like the Tawallah Valley iron, as an eotaxite, or, if it is regarded as having a too well-developed octahedral structure for this, as a microoctahedrite. 